\title{
El rocoto en tiempos de la globalización
}

Recibido: 04/10/2016

Aprobado: 07/11/2016

Humberto Rodríguez Pastor
Universidad Nacional Mayor de San Marcos
< hrodriguez2541937@hotmail.com >

\section{RESUMEN}

El rocoto, entre las variedades de ajíes en el Perú, es un fruto picante muy especial entre sus sembradores y consumidores. En muchos lugares serranos cuando buscan algo que tenga fuego y queme el paladar, solo buscan rocoto. Y si está en los huertos caseros es una planta bien tratada, y como es de espíritu sensible se le debe tratar con cariño; de lo contrario no da frutos pungentes, es vengativo. Si en el huerto casero hay muchos frutos se ofrecen de regalo a los parientes y a los vecinos y hasta a las aves rocoteras. Hay toda una pedagogía para enseñar a los nińos cómo consumirlo y de otro lado cómo debe ser presentado a los comensales. El batán es tradicional compañero del rocoto y de la milenaria cocina andina. El rocoto va adquiriendo importancia ya se consigue envasado y ya tiene demanda mundial, cada vez se exporta más; se va a otros lares, pero su espíritu andino no migra.

Palabras Clave: Perú, ají peruano, rocoto serrano, huerto casero.

\section{"El rocoto" in times of globalization}

\section{ABSTRACT}

The rocoto, among the varieties of peppers in Peru, is a very special spicy fruit between its sowers and consumers. In many Andeans places when they look for something that has fire and burns the palate, they only look for rocoto. And if it is in the home gardens it is a well-treated plant, and as it is of a sensitive spirit it must be treated with affection; Otherwise it does not bear pungent fruits, it is vengeful. If in the home garden there are many fruits are offered as gifts to relatives and neighbors and even rocoteras birds. There is a whole pedagogy to teach children how to consume it and on the other hand how it should be presented to the diners. The batán is a traditional companion of the rocoto and the millenary Andean cuisine. The rocoto is gaining importance is already achieved packaging and has global demand, is increasingly exported, He goes to other homes, but his Andean spirit does not migrate.

KeYwords: Peru, Peruvian chili, rocoto serrano, home garden. 
E 1 rocoto, como otros ajíes, tiene una fuerza histórica que ha permitido que subsistan a pesar de que oficial y estatalmente han sido olvidados por ser de consumo de los indios; esto ha cambiado en las últimas décadas al ser nuestro país un atractivo gastronómico y al participar el Perú en los fenómenos de la globalización. Así que los Capsicum $s p$. viven en tiempos que perduran con intensidad entre sectores tradicionales de la sociedad y comienzan a ser demandados dentro del mercado internacional y no solo como un insumo atractivo o curioso al paladar. Esta ponencia fundamentalmente etnográfica muestra gran parte de esta nueva realidad.

\section{Características}

El rocoto es sobre todo serrano y solo en el departamento de Tacna, en la parte costeña, también se produce este Capsicum pubescens. Tal es su nombre científico. En Bolivia lo llaman locoto y hasta hay un poblado denominado Locotal (Chapare, Cochabamba). La palabra en quechua es rukutu o lucutu; en México lo nombran como chile de cera o chile manzano y Garcilaso de la Vega lo denominó rocotuchu.

Es un arbusto de un metro a metro y medio, posible de sembrar durante todo el año y su producción de frutos es permanente. Este producto tiene forma de manzana y puede ser de color rojo, amarillo o verde, hay el que combina verde y rojo. No conocemos rocoto muy chico, su piel es carnosa y su pungencia dulzona. Otra particularidad es que el mayor fuego se halla en las venas y en sus pepas de color muy oscuro casi negras. Se caracteriza, y de ahí su nombre, por tener las hojas pubescentes (vellosas), además de flores de color violeta. Estos frutos son buscados no solo por los humanos, hay pájaros rocoteros que son los mismos que se interesan por el maíz. Ningún Capsicum sp. que en cualquier grado tenga capsaicina $\left(\mathrm{C}_{18} \mathrm{H}_{27} \mathrm{NO}_{3}\right)^{1}$ trasmite su picor a las aves pues éstas no tienen, como los mamíferos, sensores biológicos que las afecte con el ardor.

El rocoto es originario de "... los Andes occidentales de Sudamérica desde donde se extendió hasta México. Se cultiva entre 60 y $3600 \mathrm{msnm}, . .$. (hay

1 Fernando Cabieses nos dice que la capsaicina tiene gran importancia en el mercado farmacológico y alimenticio. "La industria médica lo requiere en la preparación de carminativos, aperitivos, tónicos, contrairritantes, rubefacientes y queseyó. La alimenticia, bien lo sabemos, prepara salsas, cayena, tabasco, páprika, y un montón de saborizantes para todos los gustos y tolerancias..." Cabieses 1995: 159). quien) ha llamado la atención acerca de la naturaleza carnosa de este ají, que rápidamente se deteriora y no permite su transporte... (León 2013, 232). No es costumbre frecuente usarlo deshidratado por los rayos solares como sí ocurre con otros ajíes (panca, mirasol, páprika); es muy usual ponerlo en la mesa como una crema.

El platillo más conocido en el que se usa esta hortaliza es el rocoto relleno. Es costumbre en los departamentos del sur peruano y también en Bolivia. Es un exceso creer que solo es arequipeño; en mercados de Cusco y otras ciudades es frecuente encontrar que se venden todos los días en los quioscos de comidas (ver anexo 1). En el cebiche es usual colocar una rebanada de rocoto con pepas que solo sirve de adorno y para la vista.

La venta del rocoto fresco en los mercados de abastos en el país la realizan las vendedoras de verduras y las que ofrecen especias, donde por igual ofrecen rocoto molido para los muy aficionados que consumen según sea su tolerancia. Otra cosa es en los supermercados donde al rocoto se le halla envasado (sachet o pomos) sea como pasta o crema con preservantes y con fechas de caducación.

La época de siembre es todo el año teniendo como ámbito un clima templado, favoreciendo una temperatura entre los $18^{\circ}$ a $20^{\circ} \mathrm{C}$ con una temperatura relativa baja; ... la zona de producción son los valles andinos. Químicamente el rocoto está compuesto por: agua, hidratos de carbono, proteínas, fibra, calcio, fósforo, hierro, caroteno, tiamina, ribofabina, niacina, ácido ascórbico, capsaicina.

El uso más conocido del rocoto es gastronómico pero tiene muchos otros más. Y esa es la intención principal de este artículo.

\section{Variedades}

Por la tradición ajicera arequipeña en la Estación Experimental Agraria Santa Rita (Arequipa) del Instituto Nacional de Innovación Agraria (INIA) recientemente se ha conservado el material genético de doscientas variedades de rocoto en las zonas altas de la provincia de Castilla por tratarse de un clima ideal. Hubo la inquietud por realizar este trabajo, pues se sabía de la desaparición de algunas de las variedades y se conocía la escasez de áreas de cultivo destinadas a este sembrío. Por eso para su propagación esta Estación facilitó la semilla del rocoto a los campesinos de la región. 
De esta noticia interesa resaltar la variedad de 200 rocotos en una sola región, cantidad bastante elevada; en ninguna otra del país sabemos que se hubiera hecho una labor investigatoria tan meritoria. En general en Perú no hay gran interés por investigar al capsicum sp., una de las pocas excepciones es el distrito de Ite en la provincia de Tacna y también en otro sentido en Adex con el interés de aumentar ls exportación del rocoto y el resto de ajíes peruanos.

De acuerdo a nuestras averiguaciones en distintos lugares del país en cuanto a las diversidades, en cada sitio son tantas que la gente no da números pero curiosamente sus consideraciones son más teniendo en cuenta el grado de picor, el aroma y los usos específicos antes que los colores y el tamaño. Veamos algunos casos.

En Characato, Arequipa, se usa el rocoto rojo y grande de más de $9 \mathrm{~cm}$ de alto y $8 \mathrm{~cm}$ de ancho para relleno. Su grado de picor es fuerte, por eso lo sancochan con sal y a veces con ceniza para sacar el ardor. También hay los rocotos medianos y pequeños menos de $8 \mathrm{~cm}$; utilizados en el llatan ${ }^{2}$ suelen ser verdes, anaranjados, amarillos o marrones, rojos, tienen un grado de picor fuerte, sus semillas como en todos los otros casos son oscuras. El chinche-ucho (chojna o chojña en aimara) es de color rojo y verde, su grado de picor es más fuerte que los demás, es de pequeño tamaño no más de $5 \mathrm{~cm}$.

En las provincias de Urubamba y Calca, Cusco, no es posible conseguir una persona que sepa las variedades de rocoto debido a que además de los oriundos y a los de los huertos (llamados malqui, considerados los más sabrosos) también llegan a los mercados el rucu$t u$ desde el valle de La Convención: la gente dice son del valle, sin precisar lugar. El mercado de Calca es el único lugar que hemos visto que el rocoto además de ser ofertado entero lo ofrecen abiertos, cortado sin venas ni pepas, ni siquiera los cortes indican que serían útiles para el rocoto relleno, pues los hacen a lo largo: de arriba abajo; mientras que para rellenarlos el corte se hace en la parte que rodea al pedúnculo, y es de tal manera que esa rodaja es usada como tapa cuando se han incorporado en el interior del fruto carne molida mezclada con maní, almendras y pasas y justo en la tapa va queso fresco que con el calor se funde.

$\overline{2}$ Se elabora con rocoto, cebolla, ajo y huatacay; mejor si es molido en batán.

\section{De huertos prehispánicos a huertos actuales}

Desde tiempos pretéritos tener un huerto en la parte trasera de las casas serranas - aunque también costeñas o selváticas - era obligado dentro de la concepción arquitectónica pre y poshispánica, pues cumplía un rol importante dentro del orden de recreo y culinario caseros; quien cocina en un hogar serrano encuentra fácilmente algunos de los ingredientes que requiere, solo tiene que sacarlos del huerto sin tener que ir a buscarlos ni al mercado ni a la tienda más cercana. Esta fácil y cómoda accesibilidad tiene una larga historia y es más conocida la de tiempos recientes — pues aún existe con intensidad-que la de los siglos prehispánicos.

En los períodos preinca e inca la gente del común que residía en pueblos y poblados mayores en los Andes, tenía su huerta que en quechua se denominaba yuyochacara y también su jardín o muya; en la primera se sembraba hortalizas y en el segundo flores. Ahora bien, el yuyocamayoc (hortelano) "se dedicaba al cultivo de más de 30 especies de yuyos u hortalizas (que) eran plantas herbáceas (...) que proporcionaban (...) hojas verdes (...) para la alimentación; (de su parte) el muyucamayoc (jardinero), se dedicaba al cultivo de una gran variedad de flores o ticca o huayta, en los jardines o muya" (Hurtado Fuertes, 1977: 852-863).

Este mismo autor señala, usando palabras de Guaman Poma de Ayala, que también el inca y "los principales de este reino" tenían sus yuyochacras y sus muyas donde, además de recrearse, sembraban "verduras, yuyos, flores y otras especies para tenerlas a mano". A pesar de que no se precisa, es difícil que no hubiera sembríos de rocoto en esos huertos del pasado.

Fray Martín de Murúa indica que en las huertas había muchísimas hortalizas y arboleda

(...) con grandísima cantidad de pájaros, como son garsas (sic) blancas y pardas, papagayos, mochuelos (búho), pitos, ruiseñores, codornices, guacamayos, jilgueros, tórtolas, patos, palomas, águilas, halcones, conejos, raposas (zorros), con las cuales tenían grandísimas recreaciones; y demás de esto tenían muchos géneros de animales amansados desde chiquitos, y entre ellos leones (¿pumas? HRP) muy mansos, que se ponían a comer con la gente, los cuales eran de gran gusto.

La información que reúne a continuación Hurtado Fuertes, más que a los huertos inmediatos en los hogares, se refiere a otro tipo de huertos donde se hacían 
experimentaciones agrícolas, no de plantas mayores sino de hortalizas como papa, maíz, llacón (o yacón), etc., las que siempre han requerido suelos de una profundidad mayor de $30 \mathrm{~cm}$. La más conocida y que es actualmente un lugar obligatorio de visita turística es Moray ${ }^{3}$.

Es de mucha importancia considerar la función principal que cumplían los huertos prehispánicos: "sembrío de hortalizas para tenerlas a mano"; ese mismo requerimiento ha facilitado que se continúe hasta la actualidad con el patrón arquitectónico de colocar huertos en la parte trasera de las viviendas. Se debe añadir que los patrones de vivienda españoles que se impusieron en costa y sierra también incluían jardines y huertos interiores.

\section{Un huerto grande ancashino}

A partir de varias descripciones de los planos de casas actuales podemos llegar a sus huertos y enterarnos de los sembríos que acogen. La primera corresponde a la colaboración de Fernando Britto ${ }^{4}$, quien nos describe el hogar de su niñez en el distrito y provincia de San Luis, en la actual región de Áncash. Es una descripción bastante pormenorizada, con énfasis en las remembranzas; sin embargo, hay que tener en cuenta que se trataba de un terreno bastante amplio, destinado a cultivos que por lo general son de huertos más pequeńos.

Cómo no considerar que con esos productos alimenticios de huerta, $\tan$ bien conocidos por las potencialidades que ofrecen en la gastronomía, quienes cocinaban en el hogar de Fernando Britto hacían manjares deliciosos que seguramente aún no se han perdido. Cómo no tener en cuenta, al mismo tiempo, que el rocoto cumplía y ayudaba en la misión de ser generosos con parientes y vecinos. En palabras de Britto: "con la abundancia de las plantas había suficiente rocoto para la familia, los vecinos y los amigos". Cómo no percibir la vinculación intimista que descubrió entre su abuelo y las plantas de rocoto: "de todos los cultivos de la huerta, la preferida del abuelo era el plantío de rocotos"; parte de sus recuerdos es reconocer la enseñanza de ese mismo abuelo que le decía que no había que tomar los rocotos maduros de las parte altas del arbusto, estaban destinados a las aves, y las de abajo eran para la casa. Conviene considerar, por

3 Moray, cerca a Maras en la provincia de Urubamba, Cusco, es una andenería que los Incas utilizaron como centro agrícola experimental.

4 La versión íntegra de la contribución de Fernando Britto nos la ofreció y se incluyó en: Rodríguez Pastor (2016: 309-312). último, que el ambiente rocotero de ese hogar convertía en inevitable que las siguientes generaciones fuesen también asiduas consumidoras.

\section{Huerto chico ancashino}

De Áncash tenemos el testimonio de Vanesa Velásquez, una estudiante ya egresada de nutrición de San Mar$\cos ^{5}$. Su experiencia ocurre en Los Cedros, en el callejón de Conchucos. Ella nos dice que:
Mi madre se levanta muy temprano y riega la raíz de la planta de rocoto conectando una manguera desde el caño, pero antes de ello prende la radio y se pone a cantar mientras realiza esa tarea casi diaria. Siempre he tenido la sensación de que el rocoto la escucha y se alegra; nunca nos ha faltado una de esas plantitas que no fallan en ofrecer su fruto rojiverde al que le tengo respeto.

Algo central que interesa captar es la estrecha vinculación entre el rocoto y las actividades cotidianas de esta familia que hemos tomado como ejemplo. Igual debe suceder en muchísimas otras en toda nuestra serranía y seguramente también en hogares de nuestra selva amazónica, donde nadie siembra ajíes, brotan solos; donde no hay vianda que lleve como ingrediente ají, el picante se lo coloca cada comensal en la medida de las dimensiones de su amor por el "fuego".

\section{Un huerto más en Cuspón, Bolognesi (Áncash)}

Este tercer caso $^{6}$ interesa por los detalles de cómo son los sembríos que nos muestran silenciosos conocimientos de técnicas de los campesinos de esta comunidad ancashina, igual que en todas las del territorio del país. Por eso nos parecen importantes estas palabras: "le ofrecen (a los sembríos del huerto, incluyendo la planta de rocoto) palabras carińosas y trato afectivo a cada rama y hoja, cual si se tratase de un niño", pues dentro de la tradición cultural andina también las plantas tienen vida, y escuchan y sienten, $y$ tienen sentimientos, y se alegran o entristecen y todo este trato determinará si esa planta

5 La versión íntegra de la contribución de Vanesa Velásquez igualmente se puede conocer en: Rodríguez Pastor (2016: 387-388). Ella fue mi alumna y presentó una corta monografía como parte del curso.

6 La versión íntegra de la contribución de Hernán Cornejo puede leerse en: Rodríguez Pastor (2016: 337-349). 
se ofrecerá en la plenitud de sus mejores ofrendas o las esconderá para quien no las trate convenientemente. En suma, el rocoto es un ser con vida y por eso interactúa con los humanos y otros seres con vida.

No es extraño que las familias con huerta se refieran al buen sabor o al mal sabor del rocoto, que la atribuyen a la manera en que ha sido cuidado. Y si no ha habido esmero y amor a continuación hay sensaciones de culpabilidades y propósitos de enmienda.

\section{Huerto-jardín en una casa arequipeña}

Un caso similar, de dimensiones menores si solo consideramos el tamaño del huerto, es el que nos ofrece Hernán Cornejo en una colaboración ya editada ${ }^{7}$. Mas con la intención de ubicar a esta familia dentro de la afición rocotera de los arequipeńos ${ }^{8}$, consideremos la opinión autorizada de Federico More quien, sin ser mistiano, vivió algunos ańos en Arequipa, donde amó sus comidas y sus picanterías a las que nunca olvidó: "La Roma, la Meca, la Ciudad Sagrada del ají es Arequipa" y previamente asegura que: "El ají es el rey de la cocina desde Arequipa hasta Potosí. Y, entre las diversas formas del ají, sobresale el rocoto arequipeño" (More, 1954). Así que no extrańa que Hernán Cornejo nos diga que : "En casa siempre lo comíamos, a todos mis tíos les gustaba y no había comida sin un rocoto entero en la mesa" no se comía otro ají. Y agrega algo notable: "los rocotos varían según el picor, no por el tamaño". Dice que en su tierra hay varias clases de rocotos: el que sirve para hacer rocoto relleno (más grande y menos picante), hay otro que es para la cocina y que parece pimiento, ya que no pica demasiado, es el que se macera y se muele, y sirve para exquisiteces como la ocopa arequipeńa; pero para comer y sazonar las comidas, las sopas, los segundos, hay un rocoto de huerta que es altamente picante.

Un uso permanente resaltado por Cornejo son los vegetales de la huerta como remedio inmediato; y al igual que Britto hace notar que el rocoto participaba en las buenas relaciones vecinales o familiares. De esta

$7 \quad$ La versión íntegra de la contribución de Hernán Cornejo se encuentra la de Britto en Ají Peruano..

8 En Characato, Arequipa, nos dijeron que lo tradicional es tener rocoto en las huertas, lo que hoy en día se mantiene vigente. En Puquio, Lucanas, Ayacucho, nos aseguraron que igualmente es tradición el rocoto en los huertos caseros, y como quien nos informaba tenía su restaurante precisaba que lo que ponía en la mesa lo compraba en el mercado; es decir, el rocoto del huerto no era para los clientes comensales. manera, ninguno deja dudas de que en sus mundillos familiares era inevitable terminar siendo aficionado al consumo de rocoto.

Otro testimonio, igualmente en una familia arequipeña, nos coloca en una dimensión diferente:

Mi tío antes tenía plantas de rocoto en su jardín, muchas que daban frutos muy buenos, pero un día al jardín entró el perro y escarbó debajo del tallo y sacó al aire la raíz de la planta y, entonces, las plantas se marchitaron y murieron todas. Desde aquel día no crece rocoto en ese jardín y si aparecen no crecen y si crecen solo es hasta cierta altura y luego se marchitan y mueren. Mi tío dice que la planta quedó resentida por no cuidarla como debía ser: una plantita es como un hijo, si no la cuidas se muere y si no le echas agua te maldice.

El personaje de esta anécdota le da características humanas a las plantas del rocoto de huerta: son vengativas, por haber sido maltratadas no crecen y si crecen no dan frutos y si no les echas agua te maldicen. Esta humanización malévola se escucha en otros lugares; pero también se dice lo contrario, el rocoto puede ser generoso y dar buen picor si es bien tratado.

Esta presencia cercana del rocoto en el hogar no ocurre solo en los lugares mencionados, en Cusco las personas que consumen, especialmente el de huerta (wirta ruqutu), lo conocen como el más picante a pesar de ser pequeño en tamaño. A ese rocoto lo nombran como:

\section{Rocoto campana \\ entra picando \\ sale repicando.}

Cornejo presenció en picanterías de Arequipa competencia entre aficionados al rocoto, quién comía más a mordiscones incluyendo venas y pepitas; y supo que a una señora que no fue fiel a su esposo la rocotearon; comportamiento similar hemos oído por todas partes y hasta en la "modernísima" Lima.,

\section{Huertos en hogares selváticos y su sembrío natural}

No hemos logrado gran información sobre huertos o jardines interiores (la denominación para uno u otro depende de sus dimensiones) en hogares de ciudades de la selva amazónica, pero los hay y son frecuentes; en ellos no faltan el ají charapita, el ají dulce y el pipí 
de mono, que son los que con más facilidad brotan en tierras de la selva alta y baja.

La versión de una familia tarapotina facilita conocer algo más sobre la existencia de los huertos y su situación actual. La señora Dolly Bartra, ama de casa de 45 años, que vive en Tarapoto, nos comenta:

Tarapoto ya no es como antes, que tenía huertas grandes, la gente tenía frutas, verduras, ají siempre se tenía a la mano. Ahora puro cemento hay por todas partes, todos los terrenos están dividiéndose entre los hijos, que también los venden. Ahora Tarapoto ya es una ciudad. Todo compran ahora, casi nadie siembra, solo en algunas casas se puede ver arbolitos de ají.

En el Perú se viven tiempos en los que la población rural disminuye y aumenta de manera considerable la población urbana, ha surgido un nuevo tipo de vivienda - surgimiento que no es reciente y que es válido para todas las regiones, ciudades y pueblos-, con casas o departamentos familiares sin huertos y, si hay jardines, su destino es principalmente para sembrar flores.

La principal forma de abastecimiento de ají en la selva es secular: tomarlo del lugar en el que ha crecido espontáneamente. Con frecuencia surgen plantitas cerca de donde residen grupos de personas, cualquiera sea su condición étnica-social-cultural, debido a que la gente come los ajíes y al defecar arroja las semillas que, con un poco de lluvia y sin ningún otro cuidado, reaparecen en plantas cuyos frutos nuevamente serán utilizados como condimento de los platillos. Quizás también ayudan en esta difusión natural y hasta en cambios en las variedades de ajíes los animales que viven de ellos: aves o insectos, llevando las semillas o trasladando el polen a otros lugares. Las mujeres de los grupos tribales - retomando la vieja hipótesis de que ellas, en las cercanías de sus casas iniciaron la domesticación consciente de ciertas plantas mientras esperaban que volviera la pareja con la pieza cazada - siembran ajíes para después cosecharlos, en lugares que saben que no serán utilizados para defecar u orinar.

\section{Producción masiva en Oxapampa, cuando ya no está en huerta}

Casi la totalidad de lo que sigue es resumen de un trabajo realizado por Miguel Valderrama que ya fue publicado?

9 Rodríguez Pastor (2014: 221-241).
Son más de 50 años que se cultiva rocoto en Oxapampa. Curiosamente no es para el consumo local sino para llevarlo al Mercado Mayorista de Lima, desde donde se distribuye a otros mercados de la capital y hasta a otros departamentos, como Arequipa y Tacna. Por este destino es que la fluctuación del precio condiciona decisiones en el lugar para seguir con el cultivo de rocoto.

A pesar de la frecuencia en nuestras comidas y a pesar del éxito de la llamada cocina peruana, se mantienen todavía muchos problemas de duda entre los agricultores de Oxapampa que siembran este capsicum. Problema que no es percibido por los chefs ni por los gastrónomos.

Los sucesos de la producción del rocoto sobrepasan los relacionados a la oferta y demanda del mercado, y se aprecian en una serie de condicionantes sociales Por eso los sembradores en grande del rocoto atraviesan por los enredos del sistema de intermediarios que acopian la producción de diversos caseríos de la provincia y fijan los precios a costa de la amenaza que se eche a perder la cosecha. A su vez hay el problema de la poca valoración del cultivo por la depredación de suelos, consecuencia del notable aumento de la población migrante. Como resultado de esta serie de asuntos desfavorables hay la orientación de ir prefiriendo cultivar otros frutos, como la granadilla de tipo colombiano.

Apreciación de los sembradores de rocotos de Oxapampa es que siendo tan importante su consumo en el Perú esta actividad podría ser rentable, sin embargo ha tenido y tiene tantos obstáculos que es mejor buscar nuevas alternativas. Esta es casi una amenaza que no se tiene en cuenta porque nos hallamos en el reino del libre comercio.

\section{Rocoto bueno para la salud}

El rocoto brinda múltiples beneficios para la salud debido al principio activo llamado capsaisina y otros más. Aunque parezca contradictorio es recomendado para tratar úlceras, colitis, gastritis, beneficia la digestión. El rocoto tiene propiedades antibacterianas y desinflamatorias. Por eso desde nuestros ancestros y aún en la actualidad se utilizan sus pepitas contra los dolores dentales y molares. En ciertas partes de la sierra es posible aún observar a mujeres con rodajas de rocoto en la sien, tienen comprobado que se va el dolor al igual que rodajas de papa, al fin y al cabo ambos son de la familia de las solanáceas. 


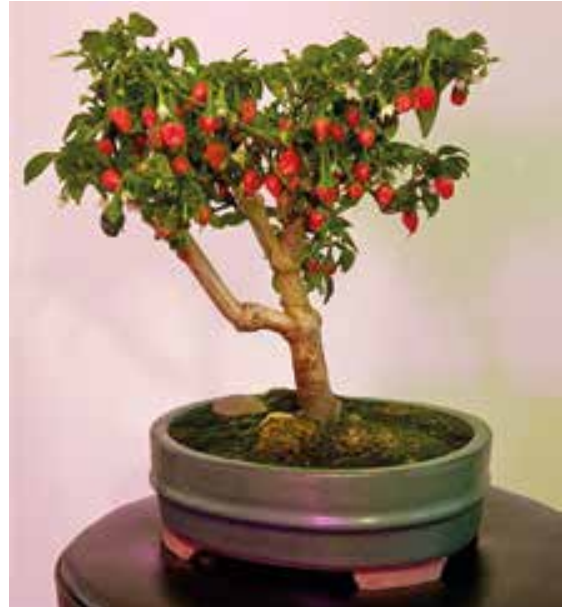

Figura 1. Bonsai de ají.

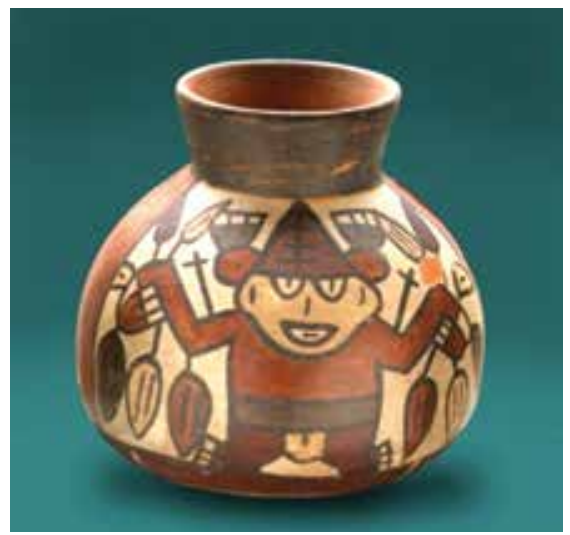

Figura 4. Ceramio nasca con ají.

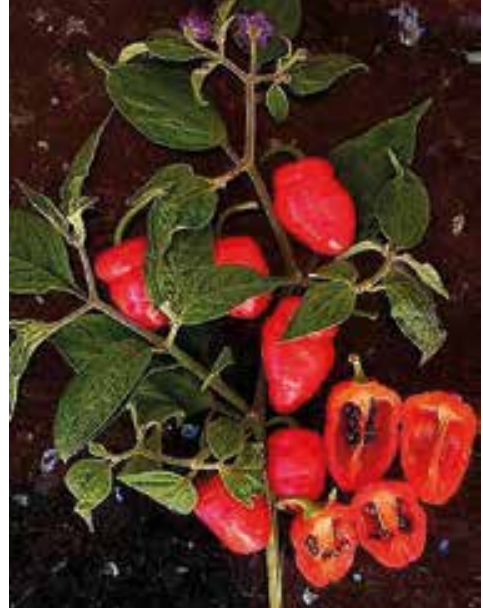

Figura 2. Rocoto en planta.

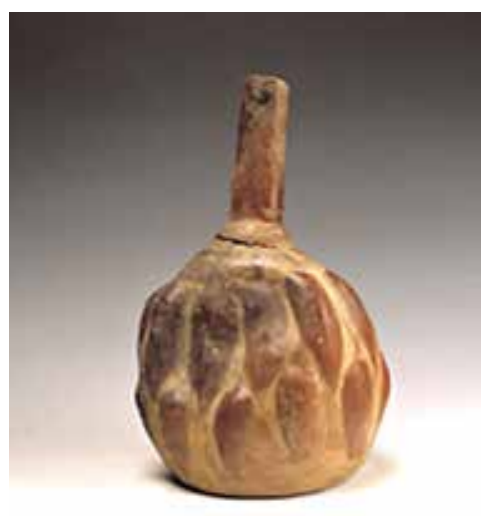

Figura 5. Ceramio mochica con ají.

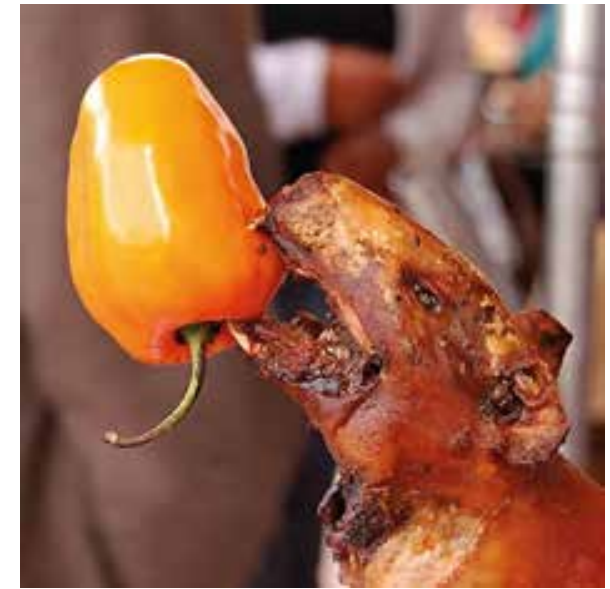

Figura 3. Cuy con rocoto.

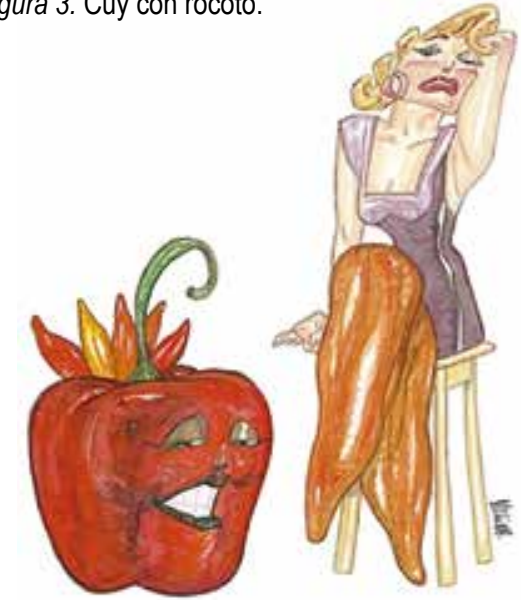

Figura 6. Propaganga
Las endorfinas que contiene este producto es útil para el tratamiento de la neuropatía diabética y la hipertensión; y es bastante conocida que es fuente de vitamina $\mathrm{C}$, ideal para la anemia, además actúa como un certero antioxidante.

Es conveniente decir que el doctor Azael Paz, de la Universidad Nacional de San Agustín y actualmente de la Universidad Cayetano Heredia (Lima), demostró que este fruto es un agente preventivo de úlceras y gastritis por el cual recibió el Premio Nacional de Medicina Básica Hipólito Unanue el año 2002.

Y el organismo público Sierra Exportadora, dependencia de la Presidencia del Consejo de Ministros, en una publicación que hizo nos dice que el rocoto: "es un excelente protector estomacal, ... tiene propiedades desinflamatorias y antibióticas, ... produce endorfinas, ... útil para combatir la neuropatía diabética, ... bueno para la hipertensión, ... fuente de vitamina $\mathrm{C}$ y ayuda para combatir la anemia y es excelente antioxidante" (Sierra Exportadora, 2012: 10-11)
De internet hemos tomado esta respuesta explicativa de una entrevista bastante útil: "Y a la pregunta original de si es bueno o hace daño comer picante le cuento que el ají es tónico para el corazón y mejora la circulación de la sangre. ¿¿Sabía que puede ayudar a evitar el infarto de miocardio por su efecto fibrinolítico al disolver fibrinas insolubles o coágulos llamados trombos? Las estadísticas prueban que la tromboembolia pulmonar es rara entre los tailandeses, grandes consumidores de ají picante. También tiene un efecto colagogo y colerético que mejora la digestión y es un poderoso estimulante para el estómago y los intestinos. Al ser un rubefaciente que produce vaso dilatación local, mejora la circulación en la zona que toca, por lo cual desaparecen el dolor y el espasmo muscular. Actualmente se están haciendo parches para el dolor en base a sus sustancias químicas... ¿`sacó ya su conclusión?” 10

10 http://lasrecetasdesilvia.blogspot.pe/2010/01/comer-picante-esbueno-o-hace-dano.html 


\section{Forma de manejar el batán para moler el rocoto}

En tanto va dejándose de usar y de conocerse, leamos primero lo que es un batán: "Batán.- Piedra dura, con una cara plana (maray), sobre la cual se extiende granos $\mathrm{u}$ otras sustancias para ser molidas por medio del roce y el golpe de otra piedra, en forma de rodillo, llamada mano o tunay" (Pulgar Vidal, 1967: 33). En buena cuenta, es un molino de mano y de fácil obtención, en los ríos se hallan los que uno cree conveniente; aunque también son construidos por los picapedreros que usan piedras de las que no se desprenda partículas o arena.

Una descripción de hace más de cuatro siglos acerca del manejo del batán con el interés de hacer del rocoto una pasta o rukutuchuta, nos la ofrece Garcilaso de la Vega:

No molían en morteros, aunque los alcanzaron, porque en ellos se muele a fuerza de brazos por los golpes que dan, y la piedra como media luna, con el peso que tiene, muele lo que toma debajo, y la india la trae con facilidad por la forma que tiene, subiéndola y bajándola de una parte a otra, y de cuando en cuando recoge en medio de la losa, con la una mano, lo que está moliendo para remolerlo, y con la otra tiene la piedra, la cual con alguna semejanza podríamos llamar batán, por los golpes que le hacen dar a una mano y a otra. Todavía se están con esta manera de moler para lo que han menester (Inca Garcilaso de la Vega, 1959: 462).

A esta descripción tal vez solo le faltaría remarcar que batanear es una labor de mujeres y que pocas veces los hombres realizan ${ }^{11}$. El peso de la piedra como media luna y la fuerza de los brazos "de la india" son los que realmente muelen, ella la hace bailar en forma cruzada, "subiéndola y bajándola de una parte a otra" produciendo un ruido rítmico; y como lo que se está moliendo se esparce a lo largo de la piedra plana, ella de cuando en cuando se detiene y con una de sus manos recoge y concentra lo molido para continuar de inmediato y hasta finalizar con la molienda, y con la otra

11 En la campińa cercana al pueblo de Urubamba, Cusco, una señora de bastantes años que se llama Lucía Alegre de Hinojosa y que tuvo como profesión hacer chicha de jora -aún la prepara pero con la ayuda de su hija Clorinda- me informó (enero 2010) que hacía medio siglo había un señor que estaba por los 95 años, y que aún por entonces molía en batán la jora de varias personas que tenían sus chicherías, con este fin iba de una en una y en el batán de cada una de ellas se ponía a batanear hasta que acababa con su trabajo por el cual, por supuesto, cobraba. Es decir: se trataba de una persona cuya profesión era moler en batán la jora que luego terminaría siendo chicha. mano sostiene la piedra ovalada. De esta manera, si se está triturando rocoto, lo ya bataneado, que siempre se hace con energía, salpica por las inmediaciones, por eso en la actualidad es muy útil una cosa tan sencilla como el mandil de plástico. El ruido que se produce al realizarse el molido se llama tangran-pungrún (Pulgar Vidal, 1967: 149) en Huánuco. Javier Pulgar Vidal la considera una voz semi-onomatopéyica por el sonido que hace quien manipula el batán y que se escucha en los alrededores.

La descripción de Garcilaso es la misma que la que hemos visto en muchas partes y hasta en nuestro hogar hace no pocas décadas. Por supuesto que el batán no solo tiene el uso que hemos presentado; se muele todo tipo de granos, incluyendo café, y hasta tierra que tiene algún color que mezclada con agua ya es pintura.

\section{Formación de nuevas generaciones de ajiceros}

Por lo que se ha leído en los párrafos anteriores se percibe que las nuevas generaciones de consumidores de ají casi siempre tienen un entorno inmediato familiar que los conduce muy naturalmente a probarlo y luego a consumirlo regularmente. Esto es endoculturarse o socializarse culinaria y gastronómicamente en un tipo de saborizador fuerte. Si no te educas desde niño en el ají, es difícil que, ya mayor, te acostumbres a su sabor intenso. De toda una nueva generación de niños en un mismo hogar no todos terminan siendo rocoteros o ajiceros. Es que hay propensiones individuales que se desarrollan siempre que encuentren el entorno conveniente.

Hay casos de precocidad ajicera como el de Paula Benites $^{12}$, quien a los tres meses probó ají y no lloró. Además de que su abuelo fue un rocotero notable, creció al lado de su abuela por la índole del trabajo de sus padres (ingenieros mineros). Ella le cocinaba y le ponía ají a sus comidas; ahora Benites es una habitúe cotidiana de cualquier Capsicum y sabe distinguir aroma y sabor en las variedades. Cuando viaja y sabe que no tendrá ají a la mano, toma sus precauciones.

En el Perú y en el mundo, la transmisión de la cultura culinaria se da principalmente en los hogares, lo que allí ocurre y lo que ellos ofrecen. En nuestras casas asimilamos, sobre todo en nuestros primeros ańos

12 La versión íntegra de la contribución de Paula Benites puede leerse en Rodríguez Pastor (2014: 101-115). 
de vida, la lengua materna, las creencias religiosas, las formas de trato entre familiares y todo lo demás; a esto se le llama la herencia social. Y eso sucede desde muy temprano, ya que nuestros sentidos (ojos y oídos) funcionan mucho antes de nuestro nacimiento. $\mathrm{Al}$ nacer se abre todo un universo del que hay que aprender y del que siempre se está aprendiendo.

Dentro de esa transmisión de todo un mundo culinario-gastronómico que ocurre de manera silenciosa y del que se hereda multitud de reglas, normas y parámetros, está en tierras andinas el amor por el sabor, el aroma y el picor del Capsicum.

Como en muchas sociedades, también en la nuestra hay formas diferentes de endoculturación de acuerdo al género. En sociedades patriarcales como la peruana, las personas de sexo femenino "nacen" para ser cocineras, por eso al lado de las madres o de otra mujer aprenden las virtudes de los ajíes y saben qué platillos los requieren, e incluso cuál de sus variedades corresponde a cada una de las viandas. Ellas, siempre más que los hombres, saben batanear el ají o el rocoto y cuidarse de que no les salpique a los ojos; sin mucho pensar conocen la cantidad exacta de la sal y de otros ingredientes y los agregan a las preparaciones aparentemente sin medirlos. Si son de Virú saben que antes de echar ají a las comidas deben sobárselo por las caderas para mejorar el sabor y la pungencia. En Nuñoa (Puno), los padres solían decirles a las niñas que si no sabían preparar el ají no iban a ser consideradas mujeres completas. En este caso las palabras se dicen y son escuchadas; en otros la misma idea se transmite sin palabras y a veces de manera violenta: " $\mathrm{ilas}$ mujercitas no deben comer ají!".

En cuanto al consumo, eso se aprende "de a poquitos", en palabras de un informante de Capachica (Puno): los niños y niñas van usando un poquito de ají hoy, otro poquito mańana, hasta que llegan a comerlo regularmente, sobre todo en ciertos platos en los que se "debe" añadir ají, como es el caso del chawlla timpu. Casi las mismas palabras han dicho otras personas de otras partes del país:

(...) los niños aprenden a comer todas estas variedades de ají, ya que sus padres los mezclan con las comidas, por eso es algo natural para ellos sentir ese picor característico de las comidas (Yungay, Ancash).

(...) como su papá no perdonaba jamás comer sin sacar del pote la salsa de ají molido con cebolla en cuadraditos, mi hijo así fue aprendiendo (Huaral, Lima).
Junto a eso hay una concepción que hay que tener en cuenta, se educa en la idea que "sin el ají la comida no es muy rica”. En el mundo rural andino no se concibe papa sin ají; y en la costa el cebiche sin ají es solo una ensalada de pescado o de mariscos. Se aprende a comer el ají viendo cómo los mayores lo disfrutan, entonces se asimila la lección de una manera semiconsciente, donde es inevitable llevar un bocado picante al paladar.

En algunos lugares, como el picor está vinculado a la fiereza o al machismo, los padres enseñan a sus hijos varones a comer ají diciéndoles que solo los hombres machos lo comen. En las chacras de Yurimaguas (Loreto) los padres les dan a sus hijos ají (challua ruro) con masato, para que resistan más el trabajo en el campo.

Parte del machismo es soportar las exigencias físicas en las labores que las requieren. Una joven contaba: "en mi caso mi padre me lo prohibía con la idea de que si lo consumía me crecerían bigotes". Para ese padre el ají era solo para hombres porque solo ellos pueden ser machos a partir de su tolerancia al ají y si una mujer lo hacía sería sancionada y le saldrían pelos sobre el labio superior.

En otros casos no hay segunda opción, como en Chivay (Arequipa) y en muchos otros lugares, donde los nińos aprenden a la fuerza a comer ají o rocoto en las comidas, porque algunos platos son picantes por la naturaleza de su preparación y cuando tienen hambre deben comerlo. Luego, por costumbre, le toman el gusto hasta hacerlo infaltable en su alimentación. La que sigue es una variación que nos narraron, sin que deje de ser una forma de injertarse en el mundo de la pungencia ajicera: "Yo aprendí a comer viendo desde pequeña a mi padre hacerlo, a él nunca le faltaba su botella de encurtido de rocoto, al principio yo solo tomaba el juguito que bota el encurtido, y así y todo picaba fuerte... así comencé”.

En el pueblo de Moche (La Libertad), los padres (y no las madres) son los que más consumen ají y los niños aprenden de ellos cuando los ven a la hora de las comidas, y remedan detalles: cómo se debe cortar el ají, de qué modo combinarlo en el plato y no chistar si hay incendio en el paladar. En este lugar, la enseñanza a la hora de la comida va junto con el aprendizaje de su cultivo según variedades, puesto que es zona de sembrío de ajíes, incluso hay una variedad que justamente se llama moche.

En muchos de los casos mencionados y en otros no indicados en estos acápites los niños tienen su primera degustación del picor ajicero no con buenas intencio- 
nes de parte de sus padres sino con el interés de sancionarlos, por ejemplo cuando llega la hora del destete. ¿Cuánto de esa primera experiencia no resulta siendo sino el inicio del escondido interés por volver a probar ají? Seguramente eso ya sucede en un momento diferente, cuando han pasado los años, la criatura ha crecido y en la cocina de la casa hay ají, en los platos que comen los mayores hay ají y gozo, el encurtido está cerca con juguito sabroso y el niño hasta es mandado a regalar o a comprar el ají o rocoto; incluso, cuando algo mayorcito come ají, recibe aplausos como si se tratara de un rito de pasaje y quizás lo es. Todo está dispuesto para que nazca y crezca un ajicero.

\section{Novedades recientes no tradicionales del uso del rocoto}

Ya se encuentra en venta como parches o como crema medicamentos cuyo principal ingrediente activo es la capsaicina. La propaganda indica que son útiles para dolores de espalda, dolores reumáticos, dolores musculares, tortícolis, dolores lumbares y ciáticos, y neuralgias.

En la versión 2015 de Mistura en el stand de gente arequipeña llamado Buñuelos Gustitos se ofrecieron buñuelos de siete cereales bañados en miel de rocoto y papaya arequipeńa.

Tampoco es extraño encontrar que se comercializa mermelada de rocoto; en Ayacucho lo elaboran las monjas de Santa Teresa; y en Urubamba, Cusco, una empresa familiar, Enkantu, también lo produce como jalea o mermelada.

La empresa Álicorp desde hace pocos años está ofreciendo al público bajo el sello Alacena salsa de rocoto que es tan solo Capsicum pubescense molido y envasado convenientemente. $\mathrm{Y}$ no es la única marca que se encuentra en los supermercados hay igualmente Sibarita, Hoja Redonda, Bell's. En estos lugares de expendio es posible hallar igualmente envasados rocoto molido congelado. $\mathrm{Y}$ en Estados Unidos envasado con la marca Inca's Food se vende Ají-Rocoto.

Una novedad es que los famosos chefs muelan su propio rocoto. En los casos que conocemos y considerando el tipo de clientes que tienen, prefieren quitarles el picor hirviéndolo dos veces, la segunda con agua nueva y luego viene el molido seguramente en una licuadora para profesionales. A diferencia de lo dicho, Teresa Izquierdo quemaba algo el rocoto en una sartén —antes se ponía en la brasa-y luego con todo, pepa $\mathrm{y}$ venas, a batanearlo.

La idea de fusión o las propuestas denominadas de autor ha conducido a que surjan muchísimas maneras de combinar el rocoto, casi con cualquier cosa comestible. Se desea así salir de lo que es frecuentemente usual o de lo tradicional. Si lo hace un chef conocido ya por eso es atractivo y sabroso. A veces son copia de lo que se ha hecho siempre en poblados no muy conocidos.

Sí es novedoso y trascendente que Adex realice en Chiclayo a fines de setiembre de 2015 la VI Convención Internacional de Capsicum coorganizado por diferentes instituciones que tienen variadas funciones, desde turísticas, como Promperú, farmacéuticas Amino Chem vinculada con Bayer, agronómicas como el Ministerio de Agricultura y Riego, Agronegocios Génesis. A este evento asistieron expertos internacionales del Capsicum.

No extraña que paralelamente se presenten a diario los comportamientos y usos del rocoto y los otros capsicum que arden en sus modalidades tradicionales. El diario La República del 14 de setiembre 2015, página 21, informa que un grupo de una ronda campesina de Celendín, Cajamarca, luego de un fallo en el juzgado legal del lugar en favor de una familia, el grupo diera por su cuenta su propia interpretación de esa decisión y sancionara a todos los integrantes de esa familia, luego de golpearlos los sumergieron en un pozo lleno de agua donde se echó ají.

\section{El rocoto se exporta ${ }^{13}$}

El ingreso del género Capsicum sp. en el mercado mundial no debe ser algo tan antiguo como la comercialización de metales, azúcar o algodón que determinaron el traslado a América de mano de obra esclava afronegra durante 3 a 4 siglos y luego de semiesclavos asiáticos (chinos culíes) en el siglo XIX. Las especies de ajíes son de producción limitada porque no es necesario su sembrío de manera amplia ni requiere de multitud de trabajadores agrícolas, ya que con un poco de picor en la olla o directamente en el plato es suficiente; casi en las mismas medidas que la sal común.

13 La información de este acápite se basa en la publicación Perfil Comercial. Rocoto, año 2012, difundido por el organismo público Sierra Exportadora dependencia de la Presidencia del Consejo de Ministros. 
Pero su demanda mundial ha ido en aumento y por lo tanto su comercialización internacional. El primer productor mundial de capsicum fresco es China, produce casi el $50 \%$ del total mundial contabilizado (casi 30 toneladas), hay que tener en cuenta la inmensa población de China y que hay regiones con pobladores altamente ajiceros como en Sichuán. Para el año 2015, según información de Adex, se exportará $52 \mathrm{t}$ de rocoto que es tan solo $0.15 \%$ de todo el género capsicum que se exporta en el mundo $(35,444 \mathrm{t})$. Las especies que más se exportan son piquillo $(15,308 \mathrm{t})$, (pimiento) morrón $(12,132 \mathrm{t}$ ), cherry $(2,022 \mathrm{t})$, jalapeño $(4,108 \mathrm{t})$, páprika $(832 \mathrm{t})$. En buena cuenta, de los mencionados, solo el jalapeńo tiene suficiente capsaicina para ser del gusto de los que toleran fuego en el paladar.

En el Perú en el año 2011 el departamento de mayor producción de rocoto fue Pasco, seguramente se trata de los sembríos oxapampinos. De las 10 toneladas producidas en el país, 65\% (6.7 t) son de ese departamento, luego siguen Puno (1.4 t), Cusco (1.1 t), Junín $(0.6 \mathrm{t})$, etc. En el cuadro que estamos utilizando no figura Arequipa. Dentro de esas $10 \mathrm{t}$ no parece que está incluido los frutos de los rocotales de los huertos caseros.

En cuanto a su exportación: "Los principales destinos... son Italia, España, Chile y Suiza, siendo Italia el primer receptor con el 80\% del total exportado en el año 2011..." (Sierra Exportadora: cuadro 8: 17). Entre las principales empresas nacionales para el género capsicum tenemos a las siguientes: Gandules Inc. Sac., Danper Trujillo S.A.C., Outspan Perú S.A.C., Camposol S.A. (Adex).

Nos parece que dentro del país el destino de toda esta producción de rocoto son dos: consumo interno e industrialización (envasado) para los supermercados incluso para la exportación. El rocoto de Oxapampa va al mercado mayorista de Lima y de allí se envía a muchos lugares del país, hemos comprobado que se lo encuentra en mercados arequipeńos y tacneños.

\section{Referencias bibliográficas}

Cabieses, Fernando (1995). Cien siglos de pan. Consejo Nacional de Investigaciones y Tecnología (Concytec), Lima.

Coe, Shopie D. (2004). Las primeras cocinas de América. FCE, México.

Garcilaso de la Vega, Inca (1959). Comentarios reales de los incas. Lima: Librería Internacional del Perú, S.A.

Horkheimer, Hans (2004). Alimentación y obtención de alimentos en el Perú prehispánico. Instituto Nacional de Cultura, Lima.

Hurtado Fuertes, Ciro (1977). "La domesticación de especies herbáceas". En: Actas del III Congreso Peruano del Hombre y la Cultura Andina (31 enero-5 de febrero de 1977). Segunda serie, tomo V. Lima, pp. 852-863.

Hurtado Fuertes, Ciro (2000). La alimentación en el Tahuantinsuyo. Instituto de Cultura Alimentaria Andina. Lima: Editorial San Marcos.

León CANALes, Elmo (2013). 14,000 años de alimentación en el Perú. Fondo Editorial Universidad de la Universidad de San Martín de Porres, Lima.

More B., Federico (1954). "Definición, exégesis y elogio del condimento y, sobre todo, el ají peruano”. En: El Comercio, 2 de septiembre.

More B., Federico (1998). Del buen comer y beber. Humberto Rodríguez Pastor (comp.). Lima: Universidad de San Martín de Porres.

Pulgar Vidal, Javier (1967). Notas para un diccionario de huanuqueñismos. Y otros peruanismos que se emplean en el departamento de Huánuco. Lima.

Rodríguez Pastor, Humberto (dirección) (2014). El aji peruano en sus regiones y pueblos. Fondo Editorial Universidad de San Martín de Porres. Lima.

Rodríguez Pastor, Humberto (2016). Ají peruano. Historia, cultura, sociedad y gastronomía. Fondo Editorial, Universidad Nacional Agraria, La Molina.

Sierra Exportadora (2012). Perfil comercial Rocoto. Presidencia del Consejo de Ministros.

Zapata Acha, Sergio (2009). Diccionario de gastronomía peruana tradicional. Fondo Editorial Universidad de Universidad de San Martín de Porres, 2da edic., Lima, octubre. 
Anexo 1

\section{Testimonio de la amplitud territorial del rocoto relleno ${ }^{14}$}

En el año 2005 realizó, nos dice Hernán Cornejo, un viaje de investigación por el sur andino en búsqueda de determinar la gran variedad de preparaciones del rocoto relleno. De Arequipa viajó a Puno por cuatro días y encontró un rocoto relleno muy similar en la preparación y presentación al arequipeño. Luego viajó al Cusco donde visitó la gran mayoría de picanterías de esa ciudad. Encontró que las diferencias - con su referente arequipeño- estaban centradas en algunos insumos: el cusqueño llevaba más zanahoria. El viaje continuó a La Paz, Bolivia, donde su búsqueda la inició en el mercado central, luego concurrió a algunos restaurantes y efectivamente comprobó que lo preparaban de una forma muy diferente. En conversaciones con algunos antropólogos y chefs en Bolivia, le indicaron que también había preparaciones muy similares en Oruro y Potosí, y no dudó en ir a esas ciudades. En Oruro y en Potosí halló una forma diferente de elaborar el rocoto. En Cochabamba vio que efectivamente había un rocoto relleno con algunas diferencias en la preparación y el relleno: fundamentalmente era de carne molida, con zanahorias, cebollas. Pero, las diferencias no eran tan acentuadas, y también se veía que los regionalismos variaban solo en lo referente a la presentación final: la preparación y la cocción eran las mismas. Finalmente, después de Cochabamba, regresó de su periplo por el sur peruano y el norte boliviano. Fueron veintiún días por buscar las variantes del rocoto relleno.

14 Resumen de una parte de la ponencia que el antropólogo Hernán Cornejo presentó en el XVII Congreso Peruano del Hombre y la Cultura Andina y Amazónica, Huacho, agosto, 2011. 